\title{
Polymorphisms of human glucocorticoid receptor gene in systemic lupus erythematosus: a single-centre result
}

\author{
Anna Bazsó ${ }^{1} \cdot$ Ágnes Szappanos ${ }^{1,2} \cdot$ Rita Rásonyi $^{1} \cdot$ Eszter Nagy $^{1} \cdot$ Abigél Farkas $^{3} \cdot$ Blanka Várnai $^{3} \cdot$ Attila Patócs $^{2,4}$. \\ Emese Kiss $^{1,5}$ - Gyula Poór ${ }^{1,5}$
}

Received: 13 September 2018 / Revised: 6 February 2019 / Accepted: 11 February 2019 / Published online: 9 March 2019

(C) The Author(s) 2019

\begin{abstract}
Background SLE is a systemic autoimmune disorder with multiple organ manifestations. Despite of the innovations glucocorticoids (GC) have still remained the first-line therapy in SLE. Besides HSD11B enzymes, intracellular glucocorticoid receptors (GR) affect tissue-specific cortisol effect and the consequent signalisation pathway. SNPs of the glucocorticoid receptor gene (NR3C1) modulate individual sensitivity to glucocorticoids. Our aim was to determine the allele frequency of the three, clinically most important SNPs in a SLE patient population in comparison to healthy volunteers and to find association with particular manifestations of SLE.

Methods We analysed results of 104 SLE patients compared to 160 healthy subjects. All patients were genotyped for the functional GR polymorphisms BclI, N363S, and A3669G. The GR gene polymorphisms were determined using allele-specific PCR and Taqman allelic discrimination assays.

Results The BclI allele frequency was lower in the SLE group compared to the healthy control group. The central nervous system and especially psychiatric symptoms developed more frequently in the BclI carriers compared to none carriers. The prevalence of the $\mathrm{A} 3669 \mathrm{G}$ polymorphism was the same in both groups, but showed a negative association with the psychiatric symptoms.

Conclusion The increased and decreased sensitivity associated with GR BclI and A3669G polymorphisms could have a pathogenic significance in SLE especial with the central nervous system and psychiatric symptoms. Improving our knowledge on the importance of $G R$ polymorphisms may reveal their pathophysiologic and therapeutic consequences.
\end{abstract}

Keywords Gene polymorphisms · Glucocorticoid receptors · Neuropsychiatric symptoms · SLE

Anna Bazsó and Ágnes Szappanos contributed equally to this work.

Anna Bazsó

bazsoanna@yahoo.com

$1 \quad$ National Rheumatology and Physiotherapy Institute, Frankel Leo út 38-40,, Budapest 1023, Hungary

2 HAS-SE Lendulet Hereditary Endocrine Tumours Research Group, Budapest, Hungary

3 2nd Department of Medicine, Semmelweis University, Budapest, Hungary

4 Department of Laboratory Medicine, Semmelweis University, Budapest, Hungary

5 3rd Department of Medicine, Semmelweis University, Budapest, Hungary

\section{Introduction}

Systemic lupus erythematosus (SLE) is a chronic, autoimmune disease which can damage many organs [1]. Despite of the survival of SLE patients has improved over the last 50 years, owing to the innovative therapies, the most appropriate scheme is absent. However, the first therapeutic option is still the glucocorticoids; treat-to-target therapy could improve the disease outcome supported by clinical trials. Lupus activity can be reduced by glucocorticoids, dramatically otherwise the side effects of long-term used glucocorticoids worsening quality of life [2]. Moreover, specific biomarkers that could predict the efficacy and side effects of glucocorticoids are still absent [3].

Both endogenous and exogenous glucocorticoids contribute to the down-regulation of disease activity and the outcome of organ damages in SLE via the intracellular glucocorticoid receptor (GR) [4]. Highly studied polymorphisms of the $G R$ gene are associated 
with altered sensitivity to glucocorticoids [5]. The N363S and BclI polymorphisms have been associated with increased, whilst the ER22/23EK and A3669G polymorphisms have been associated with decreased glucocorticoid sensitivity [6].

The glucocorticoid receptor sensitivity can show a high degree of individual differences [7]. Furthermore, SNPs may alter the sensitivity for endogenous glucocorticoids, therefore may have significance in the pathomechanism of SLE [8]. Our aim was to assess the association between the BclI, N363S, and A3669G GR gene polymorphisms, and parameters and clinical manifestations of SLE.

\section{Materials and methods}

\section{Patients}

$G R$ gene polymorphisms were analysed in 104 patients diagnosed and regularly followed-up tracked with SLE at the National Institute of Rheumatology and Physiotherapy. The control group contained 160 healthy individuals from the Hungarian population. In the SLE group, patients who have been presented with glucocorticoid therapy were selected. In the SLE group the female to male ratio was $89 \%$, whilst in the control group was $69.37 \%$. The patient's average age was $47.9 \pm 13.1$ years, whilst in the control population this ratio was $52.73 \pm 14.7$ years. The average age at the diagnosis of SLE was $31.1 \pm 13.2$ years (Table 1 ).

All members of the SLE and healthy control groups were Caucasians origin. The research was approved by the Local Ethical Committee of Semmelweis University (SE TUKEB 12/ 2013). Agreed written consent was obtained from all patients.

\section{Clinical and immunoserological analyses}

SLE was classified as per the more recent 2012 SLICC-ACR (Systemic Lupus Collaborating Clinics revised and validated the American College of Rheumatology) criteria [9]. Particular manifestations of SLE - if have been ever presented from the onset of the disease - were selected and defined as in the classification criteria. Regarding neuropsychiatric manifestation we used the ACR Ad Hoc Committee on

Table 1 Demographic characteristics of the study population

\begin{tabular}{lll}
\hline & Patients & Controls \\
\hline Number of patients & 104 & 160 \\
Female/male & $93 / 11$ & $111 / 49$ \\
Average age at the time of the study (year) & $47.9 \pm 13.1$ & $52.7 \pm 14.7$ \\
Average age at the onset of the disease (year) & $31.1 \pm 13.2$ & \\
\hline
\end{tabular}

Difference betewen the two groups are not significant as determined by Student's $t$ test neuropsychiatric lupus nomenclature as providing a definition of 19 manifestations [10].

In addition the following immune serology parameters were tested in all patients: anti-dsDNA antibody, antiribosomal-P-protein antibody, anti-chromatin antibody, antiC1q antibody, anti-SSA, and anti-SSB were tested by ELISA (ORGENTEC Diagnostika GmbH, Mainz, Germany). Anti-Sm antibody, anti-cardiolipin antibody IgG, anti-beta2-GPI antibody IgM, and IgG were tested by ELISA (INOVA Diagnostics, San Diego, CA, USA). Serum complement $\mathrm{C} 3$ and $\mathrm{C} 4$ were tested by nephelometry (Siemens Healthcare Diagnostic Products GmbH, Marburg, Germany). Lupus anti-coagulant was tested according to international recommendation.

\section{DNA extraction and genotyping of GR gene polymorphisms}

Genotyping of the BclI, N363S, and A3669G polymorphisms was performed in peripheral blood DNA isolated with commercially available DNA Isolation Kit (QIAamp DNA Blood Mini Kit (QiampDNA Blood Kit, Qiagen, USA). Genotypes for the BcII and the N363S variants were determined by allelespecific polymerase chain reaction (PCR) as earlier reported [11-13]. Genotypes for the A3669G polymorphism were analysed using a primer-probe set purchased as predesigned Taqman allelic discrimination assay according to the manufacturer's instructions (Applied Biosystems, Applied Biosystems Group 850 Lincoln Center Drive Foster City, CA) on a 7500 Fast Real-Time PCR System (Applied Biosystems). Genotypes of the GR gene, BclI, N363S, and A366G, were compared between SLE patients to a control group consisting of 160 healthy individuals.

\section{Statistical analysis}

For statistical analysis Statistica software (7.0 version, Statsoft Inc.) was used. The Hardy-Weinberg balance was tested and did not show alteration for any polymorphisms. The differences between allele frequencies and prevalence of various symptoms were evaluated by chi-squared or Fischer exact tests. The demographic data were analysed by Student's $t$ test. Significant results were defined if $p$ value was less than 0.05 .

\section{Results \\ Demographic findings and immunoserological parameters}

The immunserological parameters of patients showed high degrees of diversity. The anti-Sm (referring for kidney and neuropsychiatric manifestation) and anti-SSA antibody 
(showing subacute cutaneous erythematosus) positivities were $25.96 \%$ and $39.42 \%$, respectively. The frequency of anticardiolipin and anti- $\beta$-2-glikoprotein I antibodies and lupus anti-coagulant were as follows: $31.73 \%, 22.12 \%$, and $21.15 \%$. The results of the main demographic findings are summarised in Tables 1 and 2.

\section{The allele frequency of Bcll, N363S, and A3669G of the $G R$ gene polymorphisms in patients with systemic lupus erythematosus and the control population}

The occurrence of BclI polymorphism in patients with SLE was significant lower than control population ( 0.26 vs. 0.35 , $p=0.025)$. The frequency of $\mathrm{N} 363 \mathrm{~S}$ and $\mathrm{A} 3669 \mathrm{G}$ polymorphisms did not alter in the patients and healthy controls (N363S 0.03 vs. $0.03, p=0.873$; A3669G 0.16 vs. $0.22, p=$ 0.179) (Table 3).

\section{The association between Bcll, N363S, and A3669G GR gene polymorphisms and clinical parameters of patients with systemic lupus erythematosus}

\section{Associations between of Bcll polymorphism and the clinical symptoms}

There was a significant association between of the psychiatrics symptoms and the carrier status of BclI polymorphism $(p=0.02)$, whilst a tendency $(p=0.06)$ with central nervous system symptoms. Patients with BclI polymorphisms suffered from neuropshichiatric symptoms more often than patients without BclI polymorphism (Table 4). No statistically significant differences were found between the BclI polymorphism and other clinical parameters of SLE.

Table 2 Immune serologic findings in SLE patients

\begin{tabular}{lc}
\hline Immunserological parameters & Prevalence (\%) \\
\hline Anti-nuclear antibody & 92.31 \\
Anti-DNA antibody & 66.35 \\
Anti-Sm antibody & 25.96 \\
Anti-C1q antibody & 5.77 \\
Anti-ribosomal protein P antibody & 4.81 \\
Anti-SS-A antibody & 39.42 \\
Anti-SS-B antibody & 17.31 \\
Anti-cardiolipin antibody & 31.73 \\
Anti- $\beta$-2-glikoprotein I antibody & 22.12 \\
Lupus anti-coagulant & 21.15 \\
Low C3 and/or C4 complement components & 6.73 \\
Anti-chromatin antibody & 37.50 \\
\hline
\end{tabular}

Table 3 Allele frequency in SLE patients and control population

\begin{tabular}{llll}
\hline & SLE & Healthy controls & $p$ value \\
\hline BclI & & & \\
CC (-/-) & $58(56 \%)$ & $62(39 \%)$ & \\
CG (+/-) & $38(37 \%)$ & $82(51 \%)$ & \\
GG (+/+) & $8(8 \%)$ & $16(10 \%)$ & 0.025 \\
Allele frequency & 0.26 & 0.35 & \\
N363S & & & \\
AA (-/-) & $98(94 \%)$ & $150(94 \%)$ & 0.873 \\
AG (+/-) & $6(6 \%)$ & $10(6 \%)$ & \\
GG (+/+) & 0 & 0 & \\
Allele frequency & 0.03 & 0.03 & \\
A3669G & & & \\
AA (-/-) & $74(71 \%)$ & $100(63 \%)$ & \\
AG (+/-) & $27(26 \%)$ & $48(30 \%)$ & $12(7.5 \%)$ \\
GG (+/+) & $3(3 \%)$ & 0.22 & \\
Allele frequency & 0.16 &
\end{tabular}

-/- no carrier, +/- heterozygote, +/+ homozygote carrier. BclI polimorphism results cytozine $(\mathrm{C}) /$ guanin $(\mathrm{G})$ swap, N363S polimorphism adenine $(\mathrm{A})$ /guanine $(\mathrm{G})$ swap, whilst the A3669G polymorphism adenine $(\mathrm{A})$ /guanine $(\mathrm{G})$ swap

\section{Associations between the N363S polymorphism and clinical symptoms}

No statistically significant association were detected between the N363S polymorphism carrier status and SLE symptoms.

\section{Association between the A3669G polymorphism and the clinical symptoms}

Impact of A3669G polymorphism contributed a strong association with the psychiatric symptoms. Contrary to the association between BclI polymorphisms and psychiatric symptoms, these symptoms occurred less frequent in patients who carried the A3669G SNP compared to noncarriers (Table 5). No other significant association between this SNP and clinical parameters were detected (Table 6).

\section{Discussion}

Systemic lupus erythematosus (SLE) is a chronic autoimmune disease with several clinical manifestations and immunological alteration [1]. The interaction of sex, environmental factors, and hormonal status, including especially the hypothalamo-pituitary-adrenal axis (HPA) alteration, contribute to the development and existing of the disease. SLE is characterised by the loss of immune tolerance, aberrations of communication, differentiation, and activation of immune cells and pathways $[1,2]$. Besides regulating metabolism, 
Table 4 Association of the Bcll polimorphism and neuropsychiatric symptoms

\begin{tabular}{lllll}
\hline & Without CNS manifestation & With CNS manifestation & Total number of patients $(n=100)$ & Prevalence of CNS manifestation \\
BclI wild type & 42 & 15 & 57 & $26 \%$ \\
Bcll carriers & 24 & 19 & 43 & $44 \%$ \\
& & & & $p=0.06$ \\
& Without psychiatric symptoms & With psychiatric symptoms & Total number of patients $(n=101)$ & Prevalence of psychiatric symptoms \\
Bcll wild type & 53 & 4 & 57 & $7 \%$ \\
Bcll carriers & 34 & 10 & 44 & $23 \%$ \\
& & & & $p=0.02$ \\
\hline
\end{tabular}

CNS central nervous system

blood pressure, inflammation, and many other processes, changes in the cortisol level influence the cognitive function, the behaviour, and the reaction to stress [14]. We hypothetised that polymorphisms of glucocorticoid receptor gene, determining augmented or suppressed sensitivity to glucocorticoids, may have pathogenic significance in the development of SLE and may alter the clinical pattern of the disease.

We have found that the prevalence of BclI polymorphism was lower in the SLE group as compared to healthy controls. These findings are in concordance with the fact that BclI polymorphism increases glucocorticoid sensitivity and may have a preventive role in the development of SLE. One interesting association was found, however, between carrier status of BclI and neuropsychiatric symptoms. These symptoms developed more frequently in the BclI-positive SLE group, and in addition, these symptoms were less prevalent in the A3669G carriers. These findings strongly agree with an earlier study of van Oosten and colleagues [15]. The BclI polymorphism increases whilst the A3669G polymorphism decreases the sensitivity of glucocorticoid receptors and may have influence on the development of psychiatric syndromes.

In SLE, genetic susceptibility and other factors also trigger one of the most frequent symptoms, particularly the depression [16]. Decreased level of the noradrenalin, serotonin, and dopamine could stand at the background of depression by biogenic amine hypothesis [17]. Also, the dysregulation of the steroid level, therefore the stress, could be a prominent factor in the development of depression and cognitive dysfunction [18]. Normally, there are some molecular patterns characteristically recognised under stress situations. These patterns trigger the glucocorticoid secretion by the HPA axis and reduce the inflammatory process by negative feedback [19]. Symptoms of patients with depression show a positive correlation with the daily circle of cortisol. In the early morning cortisol triggers the symptoms but there is a behavioural relief in the evening hours [20]. In major depression changing GR sensitivity of the immune cells could lead to the dysregulation of the HPA-axis negative feedback. The alteration in the sensitivity of the receptors seems to be a critical point in the pathomechanism, whilst the role of the changed factors of the decreased expression of the receptors is controversial [21]. The altered tissue-specific cortisol level has a prominent influence on the mood, cognitive functions, the behaviour, and the reaction to stress [22]. Patients with bipolar affective disorders react intensively to the stress even in remission. Therefore, the insufficient anti-inflammatory response results increased concentration of inflammatory parameters. Moreover, there is a strong association between the increased number of the inflammatory cytokines produced by exaggerated microglial cell activity and the psychiatric disorders [23]. These cytokines could influence nerve cells producing serotonin and glutamate and resulting in a dysregulation of the homeostasis and lead to the depression. Taken together, there is a strong importance of the HPA-axis regulation and the GR sensitivity for cortisol behind the neuroimmunological mechanism [19, 20].

The elevated cortisol concentration could play also an important role in some other neuropsychiatric diseases [24]. There are a strong association between elevated cortisol level and the enlarged adrenal gland, therefore the HPA-axis hyperactivity, and psychosis. Also, there is a correlation between the elevated cortisol and the changes of the hypocampal structures in

Table 5 Association of A3669G polimorphism and psychiatric symptoms

\begin{tabular}{llccc} 
Table 5 & Association of A3669G polimorphism and psychiatric symptoms & \\
\hline & Without psychiatric symptoms & With psychiatric symptoms & Total number of patients $(n=101)$ & $\begin{array}{l}\text { Prevalence of } \\
\text { psychiatric symptoms }\end{array}$ \\
\hline A3669G wild type & 58 & 13 & 71 & $18 \%$ \\
A3669G carriers & 29 & 1 & 30 & $3 \%$ \\
& & & & $p=0.04$ \\
\hline
\end{tabular}


Table 6 Statistical analysis of GR gene polymorphisms (BclI, $\mathrm{N} 363 \mathrm{~S}, \mathrm{~A} 3669 \mathrm{G}$ ) and clinical parameters of systemic lupus erythematosus

\begin{tabular}{llll}
\hline & BclI $(p$ value $)$ & N363S $(p$ value $)$ & A3669G $(p$ value $)$ \\
\hline Arthritis & 0.78 & 0.17 & 0.24 \\
Arthalgia & 0.08 & 0.67 & 0.21 \\
Butterfly rash & 0.42 & 1.00 & 0.66 \\
Photosensitivity & 0.97 & 1.00 & 0.87 \\
Raynaud's syndrome & 0.37 & 0.17 & 0.10 \\
CNS manifestation & 0.06 & 0.10 & 0.18 \\
Psychiatric symptoms & 0.02 & 0.59 & 0.04 \\
Kidney involvements & 0.85 & 0.66 & 0.24 \\
Cardiovascular symptoms & 0.37 & 0.21 & 0.56 \\
\hline
\end{tabular}

patients suffered by psychosis [23, 24]. Furthermore, there are coexistence between the concentration of the cortisol and the epileptic seizure onset [25-27]. An elevated corticosteroid level has been measured in meningoencephalitis compared to healthy population [28]. In Guillan-Barré syndrome, the changes of cortisol could influence the outcome of the disease [29].

In our research, we have found an association of the BclI polymorphism with the SLE patients suffered by psychiatric symptoms. We share Vivlar et al. agreement about that it is an important question to consider if the nature of the NP manifestations is vascular or inflammatory. The neuropsychiatric nomenclature of SLE (NPSLE) diagnosis may be added by presence of disease activity, presence of autoantibodies, and other confounding factors [30-32]. We have selected the neurological and other manifestations under analysis if have been ever presented. The average disease duration was 20.12 (2.6 \pm 14.3) years, and in this period, the clinical symptoms usually have already appeared - especially in the first 5 years - in SLE. Therefore, new neurological symptoms are unexpected in further follow-up.

In contrast, there was a negative correlation between of the A3669G and SLE patients with psychiatric symptoms. Spijker et al. have found that A3669G SNP was also attributed a protective role in bipolar depression [33]. Unfortunately, we could not analysis the coherence of the manifestations (targeting mood disorders, stroke, psychosis, cognitive impairment, seizures, or headaches) and GR SNPs as the low eligible numbers of patients in the different classified subgroups of patients with CNS manifestation. Although, there were no difference between the SLE and control population in the prevalence of $\mathrm{N} 363 \mathrm{~S}$ and $\mathrm{A} 3669 \mathrm{G}$ alleles.

To summarise, we found that BclI and A3669G polymorphism could influence the development or modulate the neuropsychiatric disorders in patients with SLE. Recent results suggest that BclI, and A3669G polymorphisms are more frequent in patients with neuropsychiatric manifestations refers to higher sensitivity to endogenous GC regulated by the tissue-specific gene expression. Moreover, results of this study could have some therapeutical consequences as exogenous GC could be effective in controlling SLE; however, it can be used only with caution when psychiatric manifestations are present.

Funding Information Open access funding provided by National Institute of Rheumatology and Physiotherapy (ORFI).

\section{Compliance with ethical standards}

Disclosures None.

Open Access This article is distributed under the terms of the Creative Commons Attribution 4.0 International License (http:// creativecommons.org/licenses/by/4.0/), which permits unrestricted use, distribution, and reproduction in any medium, provided you give appropriate credit to the original author(s) and the source, provide a link to the Creative Commons license, and indicate if changes were made.

Publisher's note Springer Nature remains neutral with regard to jurisdictional claims in published maps and institutional affiliations.

\section{References}

1. Rekvig OP (2018) Systemic lupus erythematosus: definitions, contexts, conflicts, Enigmas. Front Immunol 9:387

2. Bazsó A, Szappanos Á, Patócs A, Gy P, Shoenfeld Y, Kiss E (2015) The importance of glucocorticoid receptors in systemic lupus erythaematosus. A systematic review. Autoimmun Rev 14:349 351

3. Ruiz-Irastorza G, Danza A, Khamashta M (2012) Glucocorticoid use and abuse in SLE. Rheumatology 51:1145-1153

4. Besedovsky HO, del Rey A (2006) Regulating inflammation by glucocorticoids. Nat Immunol 7:537

5. Manenschijn L, van den Akker EL, Lamberts SW, van Rossum EF (2009) Clinical features associated with glucocorticoid receptor polymorphisms. An overview. Ann N Y Acad Sci 1179:179-198

6. Vitellius G, Trabado S, Bouligand J, Delemer B, Lombès M (2018) Pathophysiology of glucocorticoid signaling. Ann Endocrinol (Paris) 79:98-106

7. Mosca M, Tani C, Carli L, Bombardieri S (2011) Glucocorticoids in sytemic lupus erythaematosus. Clin Exp Rheumatol 29:S126-S129

8. Zou YF, Xu JH, Pan FM, Tao JH, Xu SQ, Xiao H, Liu S, Cai J, Lian L, Chen PL, Wang DG, Liu SX, Liang CM, Ye QL, Tian G, Wu M, 
Gu YY, Pan HF, Su H, Ye DQ (2015) Glucocorticoid receptor genetic polymorphisms is associated with improvement of healthrelated quality of life in Chinese population with systemic lupus erythematosus. Clin Rheumatol 34:1537-1544

9. Petri M, Orbai AM, Alarcón GS, Gordon C, Merrill JT, Fortin PR, Bruce IN, Isenberg D, Wallace DJ, Nived O, Sturfelt G, RamseyGoldman R, Bae SC, Hanly JG, Sánchez-Guerrero J, Clarke A, Aranow C, Manzi S, Urowitz M, Gladman D, Kalunian K, Costner M, Werth VP, Zoma A, Bernatsky S, Ruiz-Irastorza G, Khamashta MA, Jacobsen S, Buyon JP, Maddison P, Dooley MA, van Vollenhoven RF, Ginzler E, Stoll T, Peschken C, Jorizzo JL, Callen JP, Lim SS, Fessler BJ, Inanc M, Kamen DL, Rahman A, Steinsson K, Franks AG Jr, Sigler L, Hameed S, Fang H, Pham N, Brey R, Weisman MH, McGwin G Jr, Magder LS (2012) Derivation and validation of systemic lupus international collaborating clinics classification criteria for systemic lupus erythematosus. Arthritis Rheum 64:2677-2686

10. The American College of Rheumatology nomenclature and case definitions for neuropsychiatric lupus syndromes (1999) Arthritis Rheum 42:599-608

11. Majnik J, Patocs A, Balogh K, Toth M, Racz K (2004) A rapid and simple method for detection of Asn363Ser polymorphism of the human glucocorticoid receptor gene. J Steroid Biochem Mol Biol 92:465-468

12. Gergics P, Patocs A, Majnik J, Balogh K, Szappanos A, Toth M, Racz K (2006) Detection of the Bcl I polymorphism of the glucocorticoid receptor gene by single-tube allele-specific polymerase chain reaction. J Steroid Biochem Mol Biol 100:161-166

13. Molnar A, Kovesdi A, Szucs N, Toth M, Igaz P, Racz K, Patocs A (2016) Polymorphisms of the GR and HSD11B1 genes influence body mass index and weight gain during hormone replacement treatment in patients with Addison's disease. Clin Endocrinol 85: $180-188$

14. Srinivasan S, Shariff M, Bartlett SE (2013) The role of the glucocorticoids in developing resilience to stress and addiction. Front Psychiatry 4:68

15. van Oosten MJ, Dolhain RJ, Koper JW, van Rossum EF, Emonts M, Han KH et al (2010) Polymorphisms in the glucocorticoid receptor gene that modulate glucocorticoid sensitivity are associated with rheumatoid arthritis. Arthritis Res Ther 12:R159

16. Koper JW, van Rossum EF, van den Akker EL (2014) Glucocorticoid receptor polymorphisms and haplotypes and their expression in health and disease. Steroids 92:62-73

17. Figueiredo-Braga M, Cornaby C, Cortez A, Bernardes M, Terroso G, Figueiredo M, Mesquita CDS, Costa L, Poole BD (2018) Depression and anxiety in systemic lupus erythematosus: the crosstalk between immunological, clinical, and psychosocial factors. Medicine (Baltimore) 97:e11376

18. Ghasemi M, Claunch J, Niu K (2018) Pathologic role of nitrergic neurotransmission in mood disorders. Prog Neurobiol S03010082(17):30044-30048
19. McEwen BS (2005) Glucocorticoids, depression, and mood disorders: structural remodeling in the brain. Metabolism 54:20-23

20. Brouwer JP, Appelhof BC, van Rossum EF, Koper JW, Fliers E, Huyser J et al (2006) Prediction of treatment response by HPA-axis and glucocorticoid receptor polymorphisms in major depression. Psychoneuroendocrinology 31:1154-1163

21. Cutolo M, Buttgereit F, Straub RH (2011) Regulation of glucocorticoids by the central nervous system. Clin Exp Rheumatol 29:S19-S-22

22. Hodes GE, Kana V, Menard C (2015) Neuroimmune mechanisms of depression. Nat Neurosci 18:1386-1393

23. Chaumette B, Kebir O, Mam-Lam-Fook C, Morvan Y, Bourgin J, Godsil BP, Plaze M, Gaillard R, Jay TM, Krebs MO (2016) Salivary cortisol in early psychosis: new findings and meta-analysis. Psychoneuroendocrinology 63:262-270

24. Girshkin L, Matheson SL, Shepherd AM, Green MJ (2014) Morning cortisol levels in schizophrenia and bipolar disorder: a meta-analysis. Psychoneuroendocrinology 49:187-206

25. Moraitis AG, Block T, Nguyen D, Belanoff JK (2017) The role of glucocorticoid receptors in metabolic syndrome and psychiatric illness. J Steroid Biochem Mol Biol 165:114-120

26. van Campen JS, Valentijn FA, Jansen FE, Joëls M, Braun KP (2015) Seizure occurrence and the circadian rhythm of cortisol: a systematic review. Epilepsy Behav 47:132-137

27. Zhang SW, Liu YX (2008) Changes of serum adrenocorticotropic hormone and cortisol levels during sleep seizures. Neurosci Bull 24: 84-88

28. Holub M, Beran O, Lacinová Z, Cinek O, Chalupa P (2006) Interferon-gamma and cortisol levels in cerebrospinal fluid and its relationship to the etiology of aseptic meningoencephalitis. Prague Med Rep 107:343-353

29. Strauss J, Aboab J, Rottmann M, Porcher R, Polito A, Ikka L (2009) Plasma cortisol levels in Guillain-Barre syndrome. Crit Care Med $37: 2436-2440$

30. Hanly JG (2017) Avoiding diagnostic pitfalls in neuropsychiatric lupus: the importance of attribution. Lupus 26:497-503

31. Hanly JG (2004) ACR classification criteria for systemic lupus erythematosus: limitations and revisions to neuropsychiatric variables. Lupus 13:861-864

32. Vivaldo JF, de Amorim JC, Julio PR, de Oliveira RJ, Appenzeller S (2018) Definition of NPSLE: does the ACR nomenclature still hold? Front Med (Lausanne) 31(5):138

33. Spijker AT, van Rossum EF, Hoencamp E, DeRijk RH, Haffmans J, Blom M, Manenschijn L et al (2009) Functional polymorphism of the glucocorticoid receptor gene associates with mania and hypomania in bipolar disorder. Bipolar Disord 11:95-101 